\title{
Jens R. Chapman, Joseph R. Dettori, Daniel C. Norwell (eds) (2009): Spine Classifications and Severity Measures: AOSPINE
}

\author{
Hardcover, 544 pp, num. figs., EUR (D) 249.95, CHF 415.00, ISBN 978-3-13-146441-5
}

\author{
Pierre H. Kehr · Jean-Paul Steib
}

Received: 11 June 2009 / Accepted: 30 June 2009 / Published online: 30 July 2009

(C) Springer-Verlag 2009

This book is useful. Sometimes we wonder why a new book? Here the answer is easy: we need it. There are so many different classifications in spine pathologies that it is difficult to follow the papers that we read. In another hand, we can have some difficulties to express our results and to present them in an oral presentation or in an article. This book is here for helping us in this work. The different classifications are well shown with simple but clear illustrations. In contrast to American way, European classifications are described and thus this book is complete and ready to be used. It seems important for this book to be on the shelves of any spine surgeons for his own expression and understanding. The book is divided in two groups:
- Spine disease severity measures: general disease, instability, deformity, degenerative, osteoporosis, infection, tumors, stenosis and heterotopic ossification.

- Spine trauma severity measures: general trauma, spinal cord injury, upper and lower cervical spine trauma, thoracolumbar and lumbosacral trauma.

This book in our library, we are ready to go on through the scientific way of spine surgery. Are there to many classifications, are they all necessary? This is another question!

Conflict of interest statement No funds were received in support of this study. 